\title{
19.9. $\begin{aligned} & \text { QUEEN'S } \\ & \text { UNIVERSITY } \\ & \text { BELFAST }\end{aligned}$
}

\section{Physicochemical tolerance, habitat use and predation are drivers of patterns of coexistence and exclusion among invasive and resident amphipods}

MacNeil, C., \& Dick, J. T. A. (2014). Physicochemical tolerance, habitat use and predation are drivers of patterns of coexistence and exclusion among invasive and resident amphipods. Freshwater Biology, 59(9), 1956-1969. https://doi.org/10.1111/fwb.12399

\section{Published in:}

Freshwater Biology

\section{Document Version:}

Peer reviewed version

Queen's University Belfast - Research Portal:

Link to publication record in Queen's University Belfast Research Portal

\author{
Publisher rights \\ (C) 2014 John Wiley \& Sons Ltd
}

This is the peer reviewed version of the following article: MacNeil, C \& Dick, JTA 2014, 'Physicochemical tolerance, habitat use and predation are drivers of patterns of coexistence and exclusion among invasive and resident amphipods' Freshwater Biology, vol 59, no. 9, pp. 1956-1969, which has been published in final form at http://onlinelibrary.wiley.com/doi/10.1111/fwb.12399/abstract. This article may be used for non-commercial purposes in accordance with Wiley Terms and Conditions for Self-Archiving.

\section{General rights}

Copyright for the publications made accessible via the Queen's University Belfast Research Portal is retained by the author(s) and / or other copyright owners and it is a condition of accessing these publications that users recognise and abide by the legal requirements associated with these rights.

\section{Take down policy}

The Research Portal is Queen's institutional repository that provides access to Queen's research output. Every effort has been made to ensure that content in the Research Portal does not infringe any person's rights, or applicable UK laws. If you discover content in the Research Portal that you believe breaches copyright or violates any law, please contact openaccess@qub.ac.uk. 
Different physicochemical tolerances, habitat utilization and predation drive patterns of coexistence and exclusion among invasive and resident amphipods

\section{In press Freshwater Biology}

\section{CALUM MACNEIL*}

Environmental Protection Unit, Department of Environment, Food and Agriculture, Isle of Man

Government, Thie Slieau Whallian, Foxdale Road, St. Johns, Isle of Man IM4 3AS

calum.macneil@gov.im

\section{JAIMIE T. A. DICK}

Institute of Global Food Security, School of Biological Sciences, Queen's University Belfast, Medical Biology Centre, 97 Lisburn Road, Belfast BT9 7BL, N. Ireland U.K.

j.dick@qub.ac.uk

*Correspondence: Calum MacNeil, Environmental Protection Unit, Department of Environment,

Food and Agriculture, Isle of Man Government, Thie Slieau Whallian, Foxdale Road, St. Johns IM4 3AS, Isle of Man.

E-mail: calum.macneil@gov.im / calummanx@hotmail.com

Keywords: amphipod, coexistence, Crangonyx pseudogracilis, exclusion, Gammarus, invasion 
Running head-line: coexistence and exclusion amongst Crangonyx pseudogracilis and Gammarus spp. 


\section{SUMMARY}

1. Patterns of coexistence and exclusion among resident and invading species in freshwaters may be generated by direct biotic interactions well as by indirect interactions with the broader abiotic and biotic environments. The North American ‘shrimp' Crangonyx pseudogracilis (Crustacea: Amphipoda) is invasive in Europe where it forms complex patterns of apparent exclusion and coexistence with resident Gammarus spp. amphipods. Using a comprehensive integrated approach, we investigated the potential biotic and interacting abiotic factors driving these distribution patterns. 2. A 2009 of 69 sites revealed that of 56 river sites containing amphipods only 6 contained $C$. pseudogracilis and these always co-occurred with Gammarus spp.. In contrast, C. pseudogracilis was the only species present in the 12 ponds/reservoirs containing amphipods.

3. Field transplant experiments in ponds and laboratory oxygen tolerance experiments revealed that C. pseudogracilis tolerates physicochemical regimes which Gammarus spp. are incapable of surviving.

4. River microhabitat sampling showed C. pseudogracilis dominating in slower, more pooled and macrophyte-dense patches, while Gammarus spp. were dominant in faster, more riffled areas.

5. Field bioassays indicated that predation of C. pseudogracilis by Gammarus spp. may be frequent in patches of rivers if/when the species meet.

6. River drift sampling revealed that C. pseudogracilis was greatly underrepresented in night/day drift relative to the Gammarus spp.. Laboratory studies showed C. pseudogracilis to be more photophobic and less active than Gammarus spp., both behaviours potentially contributing to low drift prevalence and consequent reduced exposure to shared drift predators.

7. These interacting factors may ultimately contribute to the coexistence, exclusion and relative distributions of C. pseudogracilis and Gammarus spp.. The former is potentially subject to intense predation from the latter if they encounter one another in the same microhabitat. However, with $C$. 
pseudogracilis being more physicochemically tolerant and displaying different habitat utilisation patterns than the Gammarus spp. in respect of the benthos and drift, such encounters are probably minimised. Hence C. pseudogracilis can persist in the same sites with the Gammarus spp., albeit in different microhabitats.

\section{Introduction}

One of the predicted major drivers of biodiversity change in freshwater ecosystems is the deliberate or accidental introduction of invasive species (Sala et al., 2000). Patterns of spatial and temporal coexistence and exclusion involving native/resident and invader freshwater animal assemblages may be driven by biotic interactions, such as competition and predation (Petren \& Case, 1996; Hill and Lodge, 1999, Strayer, 2009; Dick et al., 2013), acting in conjunction with other, more indirect mechanisms, such as differential physicochemical tolerances and habitat use (Settle \& Wilson, 1990; Didonato \& Lodge, 1993; Larson et al., 2009; MacNeil \& Dick, 2011). The relative roles of inter-specific interactions and abiotic influences must be unravelled if we are to understand the potential impacts of invaders on resident species, and ultimately predict the structure and functioning of invaded freshwaters (Strayer \& Dudgeon, 2010; Gallardo \& Aldridge, 2013; MacNeil et al., 2013). Studies which investigate factors influencing such community patterns often consider biotic or abiotic factors in isolation or, at best, consider single biotic factors interacting with single abiotic factors (Dick \& Platvoet, 1996; MacNeil et al., 2004). More comprehensive studies of native/resident and invader macroinvertebrate distribution patterns, that consider the roles of multiple biotic and abiotic factors interacting against a variety of habitat templates and spatiotemporal scales, remain very scarce. We used a combination of integrated field surveys and field/laboratory experiments to identify and investigate the influence of such factors on the distribution patterns of a recent invader relative to two resident species. 
Freshwater amphipods are global invaders, arriving in new catchments both by accidental introductions with shipping and other vectors and by deliberate introductions for aquaculture, angling and ecological experiments (Conlan, 1994; Dick et al. 1997; MacNeil et al. 1999, 2009, 2011; Leuven et al., 2009). The North American amphipod Crangonyx pseudogracilis has in recent decades invaded many British freshwaters (Gledhill et al., 1993). An almost mutually exclusive distribution of C. pseudogracilis relative to Gammarus spp. amphipods is evident at large geographical scales in N. America (Barton \& Hynes, 1976; J. Holsinger personal communication), and in Europe has been observed between and within individual river catchments and indeed within individual rivers (Holland, 1976; Pinkster et al., 1992; Cao et al., 1996; Dick, 1996). C. pseudogracilis is commonly found in slow flowing rivers and ditches, ponds and canals where Gammarus spp. are absent (Holland, 1976; Gledhill et al., 1993; MacNeil et al., 2000) and this pattern has been ascribed to superior physicochemical tolerances of C. pseudogracilis relative to Gammarus spp., such as the ability to survive lower organic water quality (Holland, 1976; Pinkster et al., 1992; MacNeil et al., 2000). Holland (1976) also proposed that C. pseudogracilis could not tolerate the fluviatile conditions of riffle areas favoured by Gammarus spp., but this was contradicted by MacNeil $(1997,2000)$ and Dick et al. (1997) who found C. pseudogracilis in fast flowing reaches of several British streams and rivers. Mesocosm experiments have highlighted the potential role of biotic interactions, such as predation, in governing relative distribution patterns of C. pseudogracilis and Gammarus spp.. These have shown severe intraguild predation (IGP; predation between potential competitors- see Polis et al., 1989) of the much smaller (8mm maximum body length) C. pseudogracilis by both Gammarus duebeni celticus and Gammarus pulex (18-20mm maximum body length) (MacNeil et al.,1999, in press). However, the role of changing physicochemical regimes in mediating predation of C. pseudogracilis by Gammarus spp. has not been investigated.

Commented [J R3]: No need for a reference here, and anyway you do not reference the sizes of the gammarids.

Commented [J R4]: If possible please update this with full citation details. 
Amphipods such as Gammarus spp. can also be subject to intense fish and wildfowl predation (reviewed in MacNeil et al., 1999). Many amphipod species are particularly vulnerable during drift, with more active species and more positively phototropic individuals most susceptible to drifting and hence exposure to drift feeding predators (Hiroki, 1980; Maynard et al., 1998). Drift behaviour of C. pseudogracilis relative to co-occurring Gammarus spp. has not been investigated, despite it having the potential to influence species coexistence or replacement by altering relative exposure to shared drift predators.

Populations of the native G. d. celticus in the Isle of Man (an island of $500 \mathrm{~km}^{2}$ in the Irish Sea) have been subject to invasion by the European G. pulex since the 1940s (Hynes, 1950; MacNeil et al., 2009). Repeated surveys during the following five decades reported these to be the only two amphipod species resident in the Island's rivers, ponds and reservoirs (MacNeil, 2006; MacNeil et al., 2009), until in 1996 C. pseudogracilis was first detected (Dick et al., 1997). Using the Isle of Man as a model invaded system, we aimed to elucidate a number of interacting factors that may account for the current patterns of macro-and micro-distribution of C. pseudogracilis relative to Gammarus spp. in freshwaters. First, we conducted a comprehensive field survey to establish Gammarus spp. and C. pseudogracilis distribution. We then: (i) used field transplant experiments in lentic systems where only C. pseudogracilis is detected to investigate if Gammarus spp. can survive under the same physicochemical regimes; (ii) via laboratory experiments, determined how such physicochemical regimes may mediate IGP of C. pseudogracilis; (iii) via intensive benthic sampling, assessed if the microhabitats of C. pseudogracilis and the Gammarus spp. differ at the 'patch' level within the same reaches of river where the amphipods co-exist and what physicochemical factors may influence this; (iv) via field bioassay experiments, assessed if IGP may be occurring within these reaches; and (v) via field drift sampling and laboratory activity and phototropism experiments, assessed drift behaviour of C. pseudogracilis relative to the Gammarus spp.. 


\section{Material and methods}

Island-wide survey for Gammarus spp. and C. pseudogracilis, and selection of sites for field experiments

Isle of Man river and reservoir/pond sites were surveyed in February 2009. In each water body $(\mathrm{n}=$ 56 river sites and $\mathrm{n}=13$ pond/reservoir sites), between five and fifteen 3 -min kick samples were taken (scaled for water body size) with kick nets (0.9 mm mesh net, 230 x $255 \mathrm{~mm}$ frame, $275 \mathrm{~mm}$ bag depth), all macroinvertebrates preserved on site in $70 \%$ ethanol and all amphipods later identified to species level. River sites were chosen on the basis that amphipods had previously been found during routine government biological water quality monitoring and the pond sites were part of a two yearly monitoring programme (MacNeil, 2006; C. MacNeil, pers. obs.). This survey also identified sites for subsequent microdistribution and field experiments, these being four pond sites containing only C. pseudogracilis (P1-4; Fig. 1, Table 1) and two river sites, one containing both $G$. d. celticus and C. pseudogracilis (Colby River site; Fig. 1) and one containing both G. pulex and C. pseudogracilis (Grenaugh River site; Fig. 1, Table 1).

Transplant experiment comparing survivorship of G. d. celticus and C. pseudogracilis in ponds and rivers

We adapted transplantation methodology from that of Turnbull \& Bevan (1995) using bioassay tubes constructed to the specifications of MacNeil et al. (2000, 2004). In each of four ponds where only C. pseudogracilis was detected (P1-P4; Fig. 1), C. pseudogracilis was collected by kicksampling, with G. d. celticus collected from a section of river containing only G. d. celticus closest to each pond; these distances varied between 1-3 km (R1-R4; Fig. 1). Each species was housed overnight separately in plastic trays with a plentiful supply of source water and substrate/leaf material. Only healthy, parasite-free, non-gravid adult $G$. $d$. celticus (11-15 mm body length) and $C$. 
pseudogracilis (4-6 mm) were chosen for experiments. Bioassay tubes were PVC pipe (length 20 $\mathrm{cm}$, diameter $5 \mathrm{~cm}$ ) covered at both ends with nylon mesh of $1 \mathrm{~mm}$ pore size (one end with screw cap). This mesh size represented a compromise between being large enough to allow free flow of water and to prevent clogging with silt/debris and being small enough to retain amphipods (Turnbull \& Bevan, 1995). Each tube was secured to a slate base by a pipe clip and supplied with 10 individual amphipods (see below), stream-conditioned sycamore (Acer pseudoplatanus) and ash (Fraxinus excelsior) leaves from the sites (Ryan, 2001), five catfish food pellets (each $0.5 \mathrm{~cm}$ in diameter) and substrate in the form of $5 \mathrm{~cm}$ long pre-washed clumps of Canadian pondweed (Elodea canadensis) and five hollow stone tubes (each $1 \mathrm{~cm}$ in diameter). This range of food items was designed to cover the omnivorous amphipod diet (MacNeil et al., 1997, 2004). Twelve bioassay tubes were deployed in each of the four ponds, six containing 10 G. d. celticus and six containing 10 C. pseudogracilis. Tubes were randomly placed throughout each pond, with each Gammarus tube tied to a Crangonyx tube, such that both species were exposed to similar microhabitats and hydrological regimes (MacNeil et al., 2004). In this way, individual tubes of each species were used as the replicate sample unit (Gibbins et al., 1994; MacNeil et al., 2004). Concurrent with this, in each of the four adjacent river sections (R1-4), six tubes containing G. d. celticus (10 individuals in each tube with identical food/substrate contents to the pond tubes) were deployed. All tubes were examined every week for two weeks, dead amphipods removed, additional food supplied and tubes replaced in the ponds/rivers. At the same time values of dissolved oxygen (long lead 50B D.O. meter Y.S.I.), biochemical oxygen demand ( $\mathrm{BOD}_{5}$ ) (standard laboratory methods, Sykes et al., 1999), conductivity (Dist WP; Hanna Instruments) and pH (Gallen Kampf meter) were obtained for each pond/river section.

Survivorships (proportion of the initial numbers arcsine transformed) of G. d. celticus in ponds and rivers were compared in a three-factor ANOVA, the factors being site (1-4), habitat type (pond or river) and time in situ (the latter factor as a repeated measure). Survivorships of G. $d$. celticus compared to C. pseudogracilis in ponds were examined in a three-factor ANOVA, the factors being site, species and time in situ (latter as repeated measure). ANOVAs were carried out using the SuperANOVA statistical package (Abacus Concepts, 1989). 
Field bioassay experiment examining IGP in river sites

The protocol was adapted from MacNeil et al. (2000, 2004). In April 2009, G. pulex and C. pseudogracilis were collected by kick-sampling the Grenaugh and G. d. celticus and C.

pseudogracilis by sampling the Colby site. The bioassay experimental protocol was identical to the pond/river transplant experiments described previously, except tubes contained $5 \mathrm{~cm}$ long prewashed clumps of F. antipyretica as opposed to E. canadensis. Eighteen bioassay tubes were deployed at each site; in the Colby site, six containing 10 G. d. celticus, six containing 10 C. pseudogracilis and six containing 5 G. d. celticus with 5 C. pseudogracilis; in the Grenaugh site, this protocol was repeated with G. pulex substituted for G. d. celticus. Species body size range was the same as in the previous experiment for C. pseudogracilis and G. d. celticus and was 10-15 mm for G. pulex. Tubes were orientated at $45^{\circ}$ to water flow, allowing free flow through the tube with minimal deposition of sediment and preventing amphipods being forced to one end of the tube (Turnbull \& Bevan, 1995). Tubes were randomly placed throughout each area, with each Gammarus tube tied to both a Crangonyx tube and mixed species tube, such that both single- and mixed-species assemblages were exposed to similar microhabitats and hydrological regimes (MacNeil et al., 2004).

Tubes were examined every week for two weeks in the Colby river, dead amphipods removed, additional food supplied, and tubes placed back on substrate. Tubes were left in situ for only one week in the Grenaugh River, due to spate conditions after this period causing the loss of many tubes. For the Colby River, survivorships of G. d. celticus in the single and mixed species tubes were compared using a two-factor ANOVA, the factors being tube type (single or mixed) and time in situ (repeated measure). This analysis was repeated for the C. pseudogracilis in the Colby site. For the Grenaugh River, survivorships of G. pulex and C. pseudogracilis in single and mixed tubes were analysed in two separate one factor ANOVAS, the factor being tube type (single or mixed). 
River microdistribution

In March 2009, we sampled a 50-m riffle-pool stretch of the Grenaugh River and the Colby River, Isle of Man (see Fig. 1 for site locations). The Grenaugh site (U.K. ordnance survey grid reference SC 315713 ) supported G. pulex and C. pseudogracilis and the Colby site (SC 222 689) supported G. d. celticus and C. pseudogracilis, with no other amphipods present (MacNeil et al., 2009). .

Water temperatures were $4.0^{\circ} \mathrm{C}$ and $5.1^{\circ} \mathrm{C}$ for the Grenaugh and Colby Rivers respectively, with $\mathrm{pH}$ values of 6.9 and 7.2, conductivity values of 187 and $259 \mu \mathrm{S} \mathrm{cm}^{-1}$ and $\mathrm{BOD}_{5}$ values of $<2$ for both sites. The average score per taxon (Armitage et al., 1983) biotic index values were 5.32 and 6.17 for the Grenaugh and Colby sites respectively, indicating good biological water quality for rivers in these regions of the Island (MacNeil, 2006). In-stream and channel edge vegetation in the Grenaugh site was dominated by willow moss Fontinalis antipyretica and the Colby site was dominated by the bryophytes Marsupella emarginata and Hyocomium armoricum (Ryan, 2001). Tree cover was sparse at both sites, visually estimated as $10 \%$ and $<10 \%$ for the Grenaugh and Colby sites respectively. Fifty random samples were taken at each site using a 0.9-mm-mesh Surber-sampler (area $0.0929 \mathrm{~m}^{2}$ ). All macroinvertebrates were preserved on-site in $70 \%$ ethanol and all Gammarus and Crangonyx adults and sub-adults retained by the net were counted.

Water depth and mean current velocity were recorded (C2 OTT flow-meter) before taking each Surber sample. Visual estimates were made for the percentage of the streambed at each site that was covered by leaf litter, macrophytes, riffles and the extent of the tree canopy. Substratum was assessed as minimum, maximum and modal dominant particle sizes and overall mean with the phi scale (Wright et al., 1984). Substrate heterogeneity was estimated as numbers of discrete substratum types (e.g. clay, silt, sand, gravel, >gravel, bedrock, macrophyte). Environmental variables were transformed to normalize distributions prior to principal component analysis (PCA; see Table 2 for details of transformations used). PCA transforms sets of correlated variables into orthogonal 'components' that summarise relationships among samples (Ehrenberg, 1982).

Correlations between component scores and \% C. pseudogracilis prevalence (arcsine transformed) 
assessed effects of environmental gradients on the distribution of Crangonyx/Gammarus. Statistical tests were carried out with IBM SPSS software version 20.

Iinfluence of dissolved oxygen levels on survivorship and IGP in Crangonyx:Gammarus spp. assemblages

The protocol followed that of MacNeil et al. (2004). At $11.5^{\circ} \mathrm{C}$, three $15-\mathrm{L}$ tanks containing a mix of filtered Grenaugh / Colby water had dissolved oxygen levels lowered to $20 \%, 30 \%$ and $40 \%$ respectively (Jenway meter 9071), by bubbling nitrogen (approximately 15-40 min). For each of the three oxygen levels $(20 \%, 30 \%$ and $40 \%), 45$ plastic $300-\mathrm{mL}$ pots were each filled to the brim with tank water and eight pots had 10 adult C. pseuodgracilis added, eight pots had 10 adult G. d. celticus, eight pots had 10 adult G. pulex, eight pots had five C. pseuodgracilis and five G.d. celticus added, and eight pots had five C. pseudogracilis and five adult G. pulex added. A substratum of clear glass beads (five $1.5 \mathrm{~cm}$ diameter beads) and leaf food (two $2 \mathrm{~cm} \mathrm{x} 2 \mathrm{~cm}$ sections of conditioned sycamore leaf) was placed in each pot containing amphipods. Size range for the two Gammarus spp. were similar to those for bioassay studies (11-15mm for G. d.celticus, $10-15 \mathrm{~mm}$ for G. pulex) and individuals of the two species were matched for body size by eye to minimise stress (Dick et al., 2002; MacNeil et al., 2004). Similarly, C. pseudogracilis adults were matched for body size by eye between the three dissolved oxygen treatments (body size range 4-6mm). These body size ranges for the three species were the same for all subsequent laboratory experiments. Five pots for each oxygen level were left empty with no amphipods, food or substrate. All pots ( $n=120,40$ per oxygen level) were then sealed with transparent airtight lids.

Visual inspection after $24 \mathrm{hrs}$ recorded the number and species of surviving amphipods in each pot and, in empty pots, final dissolved oxygen levels were recorded at the end of $24 \mathrm{hrs}$ to assess changes in oxygen concentration during the course of the experiment. Survivorship of $C$. 
pseudogracilis was analysed in a two factor ANOVA, the factors being oxygen, treatment (by itself or with G. d. celticus or G. pulex). Survivorship of each Gammarus species was analysed in two separate two factor ANOVAs, the factors being oxygen and treatment (by itself or with $C$. pseudogracilis).

Drift behaviour of C. pseudogracilis relative to Gammarus spp.

During October 2009, in the Colby and Grenaugh sites, five day and night drift samples were taken in each site using drift nets $(30 \times 25 \mathrm{~cm}$, mesh size $0.5 \mathrm{~mm})$ placed in both mid-channel riffle areas and channel margin areas, with sampling at noon and one hour after sunset, both for 3 hrs (see MacNeil et al., 2003). Within 24 hrs, benthic samples of five 3-minute kicks per site were taken with kick nets ( $23 \times 25 \mathrm{~cm}, 0.9 \mathrm{~mm}$ mesh). In the laboratory, amphipods were identified to species and counted. Kick sample data were used to calculate the ratio of C. pseudogracilis: G. d. celticus in the benthos of the Colby River and C. pseudogracilis: G. pulex in the Grenaugh River. Observed numbers in the drift of C. pseudogracilis and G. d. celticus in the Colby and of C. pseudogracilis and G. pulex in the Grenaugh were then compared using $\chi^{2}$ goodness of fit tests, with expected numbers generated from the benthic ratios in the Colby and Grenaugh respectively.

Sstudies of behaviours linked to amphipod drift prevalence

Amphipods were collected from the Colby river site in October 2011 and acclimatised for 5 days in $5^{\circ} \mathrm{C}$ aerated river water in aquaria $(100 \times 50 \times 20 \mathrm{~cm}$, length $\mathrm{x}$ weight $\mathrm{x}$ height), supplied with leaf litter, under a light: dark regime appropriate for the time of year.

The protocol for the phototropism experiment was adapted from Hinsbo (1972), Maynard et al. (1998) and MacNeil et al. (2003). Aquaria (40 x 20 x $20 \mathrm{~cm}$ ) were filled to $10 \mathrm{~cm}$ with Colby 
river water $\left(10.5 \mathrm{mg}^{-1} \mathrm{O}_{2}\right.$ and $\left.5^{\circ} \mathrm{C}\right)$ and divided into a light half $(100-\mathrm{W}$ illumination $)$ and a dark half (complete black plastic covering), with a black plastic divider separating the tank in half, from a few centimetres above the tank bottom to the water surface. For each trial, 10 adult amphipods were spooned into the centre of the tank, the plastic divider slid into place and the amphipods allowed $10 \mathrm{~min}$ to settle. Then every 30s for $10 \mathrm{~min}$, the number of amphipods in the light half was recorded. The experimental groups (all $n=5$ ) were: 1) 10 C. pseudogracilis, 2) 10 G. d. celtcius, and 3) $10 \mathrm{G}$. pulex. Percentages (arsine transformed) of amphipods in the light were examined in a two-factor ANOVA ('species' and 'time', the latter as a repeated measure).

The activity experiment was adapted from Maynard et al. (1998) and MacNeil et al. (2003). Twenty-four hours before observations individual adult amphipods were placed in $100 \mathrm{~mL}$ of Colby river water in a circular container $(12 \mathrm{~cm}$ diameter) with a line drawn down the middle of the bottom. In both the light (same illumination as previous) and dark (infra-red viewer), activity level was determined as the number of crosses of the line in $6 \min$ (three bouts of $2 \min$ with $2 \mathrm{~min}$ interval periods). Experimental groups were: 1) C. pseudogracilis $(\mathrm{n}=20) ; 2)$ G. d.celticus $(\mathrm{n}=20)$ and 3) G. pulex $(\mathrm{n}=20)$. Activity levels (number of line crosses $\log _{10}(\mathrm{x}+1)$ transformed) were examined in a two-factor ANOVA ('species' and 'light level').

\section{Results}

Island-wide survey for Gammarus spp. and C. pseudogracilis, and selection of sites for field experiments

The island-wide survey (69 sites) revealed that of 56 river sites containing amphipods 21 contained only G. d. celticus, 27 contained only G. pulex and six contained both Gammarus spp.. Only six river sites contained C. pseudogracilis and always co-occurring with Gammarus spp. (two sites cooccurring with G. d. celticus and four co-occurring with G. pulex). In contrast, C. pseudogracilis 
was the only amphipod species found in ponds (12 out of 13 pond sites, with the remaining site containing no amphipods).

Transplant experiment comparing survivorship of G. d. celticus and C. pseudogracilis in pond sites

G. d. celticus survivorship was significantly lower in pond habitats compared to immediately adjacent river habitats $\left(\mathrm{F}_{1,40}=12.5, P<0.0001\right.$; Fig $\left.2 \mathrm{a}\right)$, with survivorship decreasing over time $\left(\mathrm{F}_{1,40}=5.2, P<0.01\right.$; Fig. $\left.2 \mathrm{a}\right)$. There was also a significant 'habitat $\mathrm{x}$ time' interaction effect $\left(\mathrm{F}_{1,40}=\right.$ $8.6, P<0.0001$ ), with survivorship decreasing faster in pond than in river habitats over time.

Whereas all four river sections showed G. d. celticus survivorship above $80 \%$ after two weeks, two ponds had less than $10 \%$ G. d. celticus survivorship and two ponds had no surviving G. d. celticus after this time. 'Site' did not have a significant effect on survivorship $\left(F_{3,40}=2.5\right.$, NS).

C. pseudogracilis survivorship was significantly higher than that of G. d. celticus in pond habitats $\left(\mathrm{F}_{1,40}=11.9, P<0.0001\right.$; Fig. $\left.2 \mathrm{~b}\right)$. Although survivorship of both species decreased over time $\left(F_{1,40}=10.1, P<0.0001\right)$, there was a significant 'species $\mathrm{x}$ time' interaction effect $\left(\mathrm{F}_{1,40}=5.3\right.$, $P<0.01$ ), as $C$. pseudogracilis survivorship remained higher than $50 \%$ in all sites and still exceeded $90 \%$ in two sites after two weeks, whereas G. d. celticus survivorship declined to near zero (Fig 2b).

Oxygen saturation was never less than $92 \%$ in any of the four river habitats and conversely never exceeded $32 \%$ in any of the ponds (Table 1 ). In conjunction with this, biochemical oxygen demand $\left(\mathrm{BOD}_{5}\right)$ was $<2 \mathrm{mgL}^{-1}$ for all four river sections, while ranging from 3-6 $\mathrm{mgL}^{-1}$ for the four ponds (Table 1).

Bioassay experiment examining IGP in river sites 
In both the Colby and Grenaugh Rivers, mean survivorship of all amphipod species in single species tubes was $88 \%$ or better (Fig 3a-b). In mixed species tubes in both rivers, C. pseudogracilis survivorship was significantly lower in the presence of Gammarus species $\left(\mathrm{F}_{1,10}=17.2, P<0.0001\right.$ for Colby and G. d. celticus and $F_{1,10}=20.1, P<0.0001$ for Grenaugh and $G$. pulex respectively; Figs. 3a, b) reducing from less than $25 \%$ after one week in the presence of G. d. celticus in the Colby river down to $0 \%$ after two weeks (Fig $3 a$ ) and down to $40 \%$ after one week in the presence of G. pulex in the Grenaugh River (Fig 3b). In contrast, for both rivers Gammarus survivorship was unaffected by the presence of $C$. pseudogracils, remaining above $90 \%$ in all mixed species tubes and not significantly differing from survivorship in single species tubes $\left(F_{1,10}=1.9\right.$, and $F_{1,10}=2.2$, both NS for the Colby and Grenaugh rivers respectively). In mixed species tubes in both rivers, $C$. pseudogracilis body parts were evident after one week. No body parts were evident in the mixed tubes in the Colby River after two weeks and it was assumed they had been eaten. In contrast, the few C. pseudogracilis cadavers recovered from single tubes were intact, as were the few G. $d$. celticus and G. pulex cadavers recovered from mixed species tubes. There was also a significant time and G. d. celticus interaction effect in the Colby River, as C. pseudogracilis survivorship declined faster in mixed tubes $\left(\mathrm{F}_{1,10}=10.0, P<0.01\right)$.

\section{River microdistribution}

For the Colby and Grenaugh samples, respectively, the first three PCA component axes accounted for $67 \%$ and $60 \%$ of variance in environmental variables respectively (Table 2). For the Colby, PC1 (35.7\%) distinguished deeper, slower, pooled areas with greater macrophyte coverage from shallower, faster, more riffle dominated patches with less macrophyte coverage. PC2 (22.9\%) distinguished patches with less complex substrates from more diverse substrates, while PC3 (8.2\%) distinguished larger substrate dominated patches from those dominated by smaller substrates. PC1 
positively correlated with the percentage of $C$. pseudogracilis present $(\mathrm{r}=0.66, \mathrm{df}=48, P<0.001$,; Fig. 4a), indicating that, in contrast to G. d. celticus, this species dominated the more sluggish, pooled parts of the river where macrophyte cover was greatest.

For the Grenaugh, like the Colby system, PC1 (30.9\%) distinguished deeper, less riffle dominated patches with greater macrophyte cover from shallower, riffle patches with sparser macrophytes. PC1 (20.3\%) distinguished patches with lower current velocity from those with faster flows, while PC3 (9.1\%) distinguished patches with a greater coverage of leaf litter from those with less leaves and fewer leaf packs. PC1 positively correlated with the percentage of C. pseudogracilis present $(\mathrm{r}=0.71, \mathrm{df}=48, P<0.0001$; Fig. $4 \mathrm{~b})$, indicating that, again similar to the Grenaugh system, in terms of relative abundance this species was found in the deeper, pooled parts of the river with densest macrophyte coverage.

Mean $( \pm \mathrm{SE})$ relative abundance of $C$. pseudogracilis was $12 \%( \pm 1 \%)$ and $26 \%( \pm 3 \%)$ for the Colby and Grenaugh Rivers respectively (4a-b) and was highly variable, ranging from 0 to $100 \%$ in sampled patches in both rivers (Fig 4a-b). In the Colby, the relative abundance of C. pseudogracilis increased with macrophyte cover $(\mathrm{r}=0.28, \mathrm{df}=48, P<0.05)$ and decreased with current velocity and percentage riffle coverage $(r=-0.62, P<0.001$ and $-0.39, P<0.01$ respectively, both $\mathrm{df}=48$ ). In the Grenaugh the species exhibited a similar pattern of micro-distribution, increasing with depth, macrophyte coverage $(r=0.28$ and 0.41 respectively, both $P<0.05$ and both $\mathrm{df}=48)$ and decreasing with current velocity and riffle coverage $(r=-0.38, P<0.01$ and $r=-0.77, P<0.001$ respectively, both $\mathrm{df}=48)$.

Influence of dissolved oxygen levels on survivorship and IGP in Crangonyx:Gammarus spp. assemblages 
Although survivorship of C. pseudogracilis when isolated from Gammarus spp. declined significantly with decreasing oxygen saturation $\left(\mathrm{F}_{2,63}=6.9, \mathrm{P}<0.0001\right.$; Fig 5a), survivorship was $100 \%$ at both $40 \%$ and $30 \%$ oxygen saturation and only decreased to $88 \%$ at $20 \%$ saturation. In contrast, both Gammarus spp. had lower survivorship than C. pseudogracilis at all oxygen levels, with both G. d. celticus and G. pulex showing survivorships of less than $20 \%$ at $20 \%$ saturation (Fig 5a). However, when Gammarus spp. were present, C. pseudogracilis survivorship declined significantly $\left(\mathrm{F}_{2,63}=17.1, P<0.0001\right.$; Fig $\left.5 \mathrm{~b}\right)$, but there was a significant 'oxygen saturation $\mathrm{x}$ amphipod treatment' interaction effect $\left(\mathrm{F}_{4,63}=6.9, P<0.01\right)$, as this decline was most pronounced at higher oxygen saturation levels, down to $62 \%$ survivorship in the presence of G. d. celticus and $46 \%$ survivorship in the presence of G. pulex respectively, at $40 \%$ saturation (Fig $5 \mathrm{~b}$ ). In contrast, C. pseudogracilis presence had no effect on the survivorship of either Gammarus spp. $\left(\mathrm{F}_{1,42}=3.7\right.$ and $\mathrm{F}_{1,42}=3.2$, both NS, for $G$. d. celticus and G. pulex respectively).

Drift behaviour of C. pseudogracilis relative to Gammarus spp.

For the Colby River, 2845 amphipods were collected, 2622 from the benthos, 33 from the day drift (12 from margins, 21 from mid-channel) and 190 from night drift (29 from margin, 161 from midchannel). Overall, the ratio of C. pseudogracilis : G. d. celticus in the benthos of the Colby river, was 1: 5.2. C. pseudogracilis was significantly underrepresented (and consequently G. d. celticus significantly overrepresented $)$ in the drift samples $\left(\chi^{2}=26.5,46.8\right.$ and 45.5 for margin night drift, mid- channel day drift and mid-channel night drift samples respectively, all $\mathrm{df}=1, P<0.0001$; Fig. 6a). For the Grenaugh River, 3970 were collected, 3621 from the benthos, 52 from the day drift (10 from margin, 42 from mid-channel) and 297 from the night drift (47 from margin and 250 from mid-channel) respectively (Fig 6b). The ratio of C. pseudogracilis : G. pulex in the benthos of the Grenaugh river was 1: 4.6. C. pseudogracilis was significantly underrepresented (and consequently 
G. pulex significantly overrepresented $)$ in the drift samples $\left(\chi^{2}=178,18.9\right.$ and 22.1 for margin day drift, mid- channel day drift and mid-channel night drift samples respectively, all $\mathrm{df}=1, P<0.0001$; Fig. 6b). No parasitized C. pseudogracilis were recovered from samples from either river and only nine G. d. celticus and four G. pulex individuals respectively were parasitized (by acanocephalans) and these all occurred in benthic samples.

Laboratory studies of behaviours linked to amphipod drift prevalence

There was a significant difference between amphipod species in the proportion of individuals in the light $\left(\mathrm{F}_{2,12}=7.4, P<0.01\right.$; Fig. $\left.7 \mathrm{a}\right)$, with a lower proportion of $C$. pseudogracilis occupying the light region than either of the two Gammarus spp. $(P<0.05$ in both cases, Fishers Protected Least significant Difference, FPLSD). There was a trend for a lower proportion of G. $d$. celticus occurring in the light than of G. pulex $(P=0.07$, FPLSD). There was a significant time effect, as all amphipods tended to become increasingly located in the dark part of tanks as the experiment progressed $\left(\mathrm{F}_{20,240}=7.9, P<0.0001\right)$, but there was no 'species $\mathrm{x}$ time' interaction effect $\left(\mathrm{F}_{40,240}=\right.$ $1.0, \mathrm{NS})$.

Activity level differed significantly among species $\left(\mathrm{F}_{2,114}=4.9, P<0.01\right.$; Fig. $\left.7 \mathrm{~b}\right)$, with $C$. pseudogracilis significantly less active than either Gammarus spp. ( $P<0.05$ in both cases, FPLSD). There was no significant difference between Gammarus spp. in activity level (both NS, FPLSD). All species were significantly more active in the dark than the light $\left(\mathrm{F}_{1,114}=5.9, P<0.01\right)$, but there was no 'species $x$ light level' interaction effect $\left(\mathrm{F}_{3,114}=1.2, \mathrm{NS}\right)$. 


\section{Discussion}

The greatest threat to freshwater biodiversity is arguably invasive species (Sala et al., 2000) or a combination of invasives and habitat degradation (Strayer \& Dudgeon, 2010). Inter-specific interactions, abiotic factors, and the combined effects of the two influence invader and native assemblage structure (Strayer \& Dudgeon, 2010; MacNeil et al., 2009; Dick et al. 2013). Unravelling the interplay of these two drivers of freshwater biodiversity change requires field and laboratory studies at scales of whole catchments down to patches within rivers/ponds, as invasive and native species may interact at these diverse scales to drive patterns of exclusion and coexistence that are scale-dependent. Thus, invaders such as G. pulex might eliminate natives (e.g. G. d. celticus) and other invaders (eg C. pseudogracilis) at the scale of patch or river (MacNeil et al., in press), but enhance species richness at the scale of the catchment or land-mass (see Dick 1996). In this study we have shown that, although drastic changes have taken place in the composition of the amphipod assemblage present (MacNeil et al., 2009), natives such as G. d. celticus, long-time residents such as G. pulex and more recent invaders such as C. pseudogracilis, can coexist in the same sites if habitat utilisation patterns differ. The 2009 survey revealed that only a single site differed in amphipod species site designations relative to the same sites sampled in an earlier, larger 2005 survey (in this case G. d. celticus being replaced by G. pulex). In all other river and lake sites, the same single and mixed species assemblage-site linkages found in 2005 persisted through to 2009 ( see MacNeil \& Dick, 2011). While there was no range expansion of C. pseudogracilis, it remained the only amphipod detected in pond/reservoir sites and was capable of persisting with both Gammarus spp. for at least several years in river sites. Some of these pond/reservoir sites are relatively isolated but many contain waterfowl, and recent experiments have shown that external transport (ectozoochory) of C. pseudogracilis on bird plumage and legs, is a possible vector enhancing the amphipod's spread (Rachalewski et al., in press). 
It is clear that C. pseudogracilis and the Gammarus spp. are not 'ecological equivalents' (see Hynes, 1954) and a scarcity of ecological equivalents occupying the same range of habitats may reduce the likelihood of species replacements via interspecific interactions (Dick, 1996). Invaders can have profound impacts on the biodiversity of small islands, such as the Isle of Man, which have fewer resident species than neighbouring mainlands (Diamond \& Case, 1986). Alternatively, these relatively impoverished communities may be capable of integrating certain types of invader with seemingly minimal community disturbance. Gore \& Milner (1990) recognised that successful colonizers possess a broad potential niche via wide environmental tolerances, and Pinkster et al. (1992) argued that the wide physicochemical tolerance of C. pseudogracilis gifts it the "potential to colonize waters currently devoid of any other gammarid species". For instance, our results indicate C. pseudogracilis has a 'supertramp' existence in the Isle of Man, capable of wide dispersal and surviving in a wide range of habitats, but being excluded from many habitats which already support diverse assemblages of resident species (see Colinvaux, 1986). Thus it persists in low-oxygen habitats such as ponds or the pooled 'margins' of rivers, which Gammarus spp. cannot tolerate, while still being capable of surviving in high-oxygen sites, such as 'patches' of good water quality (see also MacNeil et al., 2000). However, our results also indicate there can be intense predation pressure from both Gammarus spp. in these patches of good water quality, further driving the 'realised niche' and ultimate distribution patterns of C. pseudogracilis manifested in the Island's freshwaters (see MacNeil et al., 2000). Thus, our study shows that $C$. pseudogracilis can persist on the same land mass as Gammarus spp. only if direct interactions with the latter are avoided, whether this be via differential behavioural mechanisms or physiological tolerance.

The ability of C. pseudogracilis to survive low-oxygen/poor water quality conditions has been noted previously (MacNeil et al., 2001; 2004), and the species has active brood care adapted to cope with such conditions (Dick et al., 1998). However, for the first time we here empirically showed that predation by the Gammarus spp. is drastically curtailed as dissolved oxygen levels fall. 
Therefore, spatial habitat heterogeneity in freshwater systems, which can produce sluggish, loweroxygen patches alongside faster flowing, higher-oxygen patches, is clearly vital to the coexistence of C. pseudogracilis with predatory Gammarus spp.. Our combined field and laboratory investigations also indicate that if freshwater habitats became increasingly stressed and environmentally degraded, with gross organic pollution and associated deoxygenated conditions, then C. pseuodgracilis could persist and possibly spread while the Gammarus spp. are eliminated. For instance, G. pulex thrives in rivers where water quality has been gradually increasing in recent decades, but in adjoining anoxic, polluted canals transplant experiments showed it cannot survive and C. pseudogracilis dominates (MacNeil et al., 2000). Many biotic indices of organic water quality such as the BMWP system used in the Isle of Man and throughout U.K. freshwaters (Biological Monitoring Working Party, 1978) group all Crangonyctidae under the same organic pollution sensitivity 'score' as the Gammaridae (Walley \& Hawkes, 1996). Our results indicate that C. pseudogracilis (representing British Crangonyctidae) should be significantly downgraded relative to both G. d. celticus and G. pulex (representing British Gammaridae) in terms of relative pollution tolerance scores.

Our drift and river microdistribution results also suggest that in behavioural terms, $C$. pseudogracils functions more as a lentic species adapted to slower flowing, darker environments than more 'riverine' species such as G. d. celticus and G. pulex. This probably reflects the origin of this species in the North American Great Lakes (Barton \& Hynes, 1976), with these behaviours still manifest in the newly colonised habitats within the Isle of Man, the British Isles and Central Europe. C. pseuodgracilis was underrepresented in the drift relative to both Gammarus spp. which probably reflected its lower activity and less positively phototropic behaviour. These results support those of Hiroki (1980), who found that more active amphipod species spent more time in the water column and therefore drifting in currents than less active species. This could mean that $C$.

pseudogracilis is far less vulnerable to shared predators such as fish and wildfowl (present in large 
numbers in both the Grenaugh and Crogga rivers - R. Selman pers. com.), which feed extensively on drifting amphipods (Newman \& Waters 1984; MacNeil et al., 1999), than either of the two Gammarus spp. within the same river sites. Although the patterns of G. d. celticus and G. pulex drift observed here closely resemble patterns observed in Northern Irish waters (MacNeil et al., 2000, 2003), a significant limitation of the current drift field study is the lack of riverine sites where only C. pseudogracilis was present. Studies of C. pseudogracilis drift from such sites would be useful in ascertaining if the presence of Gammarus spp. was suppressing such drift and/or altering C. pseudogracilis drift behaviour.

Studies of biological invasions, perhaps understandably, tend to focus on threats to biodiversity through the elimination and replacement of native/resident species. However, our study is an example of a resident community being capable of integrating an invader, but only if specific spatio-temporal factors prevail. Our range of methods allows understanding, and potentially prediction, of how invaded assemblages can be structured, while highlighting the need to consider multiple variables when considering the reasons behind observed patterns of coexistence and exclusion.

\section{Acknowledgments}

We thank Dr. Richard Selman, Senior Biodiversity Officer (DEFA, Isle of Man Government) for information on fish and wildfowl. We thank James Singleton and Neil Longwith of the Government Laboratory, Isle of Man, for processing chemistry samples. We thank two anonymous referees whose comments greatly improved this manuscript.

\section{References}


Abacus Concepts (1989) SuperANOVA. Abacus Concepts, Berkeley.

Armitage P.D., Moss D., Wright J.F. \& Furse, M.T. (1983) The performance of a new biological quality score system based on macroinvertebrates over a wide range of unpolluted running water sites. Water Research, 17, 333-347.

Barton DR. \& Hynes, H.B.N. (1976) The distribution of Amphipoda and Isopoda on the exposed shores of the Great Lakes. Journal of Great Lakes Research 2: 207-214.

Biological Monitoring Working Party (1978) Final Report: Assessment and Presentation of the Biological Quality of Rivers in Great Britain. Water Data Unit, Department of the Environment, London.

Cao Y., Bark A.W., Williams W.P. (1996) Measuring the responses of macroinvertebrate communities to water pollution: a comparison of multivariate approaches, biotic and diversity indices. Hydrobiologia, 341, 1-19.

Colinvaux P. (1986) Ecology. Wiley, New York

Conlan K.E. (1994) Amphipod crustaceans and environmental disturbance: a review. Journal of Natural History, 28, 519-554.

Diamond J.M. \& Case T.J. (1986) Community Ecology. Harper and Row, New York.

Dick J.T.A. (1996) Post-invasion amphipod communities of Lough Neagh, N. Ireland: influences of habitat selection and mutual predation. Journal of Animal Ecology, 65, 756-767 
Dick, J.T.A. \& Platvoet, D. (1996) Intraguild predation and species exclusions in amphipods: the interaction of behaviour, physiology and environment. Freshwater Biology 36, 375-383.

Dick J.T.A., Nelson N. \& Bishop J.D.D. (1997) Introduction experiments with Gammarus spp.

(Crustacea: Amphipoda) in the Isle of Man (British Isles), 1949-1995. Journal of Zoology London, 242, 209-216.

Dick J.T.A, Faloon S.E, Elwood R.W. (1998) Active brood care in an amphipod: influences of embryonic development, temperature and oxygen. Animal Behavior, 56, 663-672.

Dick J.T.A., Platvoet D. \& Kelly D.W. (2002) Predatory impact of the freshwater invader Dikerogammarus villosus (Crustacea:Amphipoda). Canadian Journal of Fisheries and Aquatic Sciences, 59, 1078-1084.

Dick J.T. A., Alexander M. \& MacNeil C. (2013) Natural born killers: an invasive amphipod is predatory throughout its life-history. Biological Invasions, 15, 309-313.

DiDonato G.T. \& Lodge D.M. (1993) Species replacement among Orconectes crayfishes in Wisconsin lakes: the role of predation by fish. Canadian Journal of Fisheries and Aquatic Sciences, 50, $1484-4888$.

Ehrenberg A.S.C. (1982) A primer in data reduction. An introduction to statistical analysis. Wiley. 
Fitter R. \& Manuel R. (1986) Collins field guide to freshwater life. Collins, London.

Gallardo B. \& Aldridge D. C. (2013) The 'dirty dozen' : socio-economic factors amplify the invasion potential of 12 high-risk aquatic invasive species in Great Britain and Ireland. Journal of Applied Ecology, 50, 757-766.

Gibbins C.N., Soulsby C. \& Merrix R.F. (1994) The impact of interbasin water transfer on invertebrate communities of the River Wear. Integrated River Basin Development, 16, 166-175.

Gledhill T., Sutcliffe D.W. \& Williams W.D. (1993) British Freshwater Crustacea Malacostraca: a Key with Ecological Notes. Freshwater Biological Association Scientific Publications No. 52. Freshwater Biological Association, Ambleside.

Gore J.A. \& Milner A.M. (1990) Island biogeographic theory: can it be used to predict lotic recovery rates? Environmental Management, 14, 737-753.

Hill A.M. \& Lodge D.M. (1994) Diel changes in resource demand: competition and predation in species replacement among crayfishes. Ecology, 75, 2118-2126.

Hinsbo O. (1972) Effects of Polymorphus (Acanthocephala) on color and behaviour of Gammarus lacustris. Nature, 238, 333.

Hiroki M. (1980) Relation between the two diel phenomena shown by freshwater gammarids - drift and vertical migration. Crustaceana, 6, 182-193. 
Holland D.G. (1976) The distribution of the freshwater Malacostraca in the area of the Mersey and Weaver River Authority. Freshwater Biology, 6, 265 - 276.

Hynes H.B.N. (1950) Preliminary report on work on freshwater species of Gammarus in the Isle of Man. Annual Report for 1949 (62) of the Marine Biological Station, Port Erin, Isle of Man.

Hynes H.B.N. (1954) The ecology of Gammarus duebeni Lilljeborg and its occurrence in freshwater in western Britain. Journal of Animal Ecology, 23, 38-84.

Larson E.R., Magoulick D.D., Turner C. \& Laycock K.H. (2009) Disturbance and species displacement: different tolerances to stream drying and desiccation in a native and an invasive crayfish. Freshwater Biology, 54, 1899-1908.

Leuven R.S.E.W., van der Velde G., Baijens I., Snijders J., van der Zwart C., Lenders R. \& Bij de Vaate A. (2009) The river Rhine: a global highway for dispersal of aquatic invasive species.

Biological Invasions, 11, 1989-2008.

MacNeil C. (1997) The ecology of freshwater amphipods: a study of invasive and native species. $\mathrm{PhD}$ thesis, The Queens University of Belfast, U.K. (unpublished).

MacNeil C., Dick J.T.A. \& Elwood R.W. (1997) The trophic ecology of freshwater Gammarus (Crustacea: Amphipoda); problems and perspectives concerning the functional feeding group concept. Biological Reviews of the Cambridge Philosophical Society, 72, 349-364. 
MacNeil C., Dick J.T.A. \& Elwood R.W. (1999) The dynamics of predation on Gammarus spp.

(Crustacea: Amphipoda). Biological Reviews of the Cambridge Philosophical Society, 74, 375-395.

MacNeil C., Dick J.T.A. \& Elwood R.W. (2000) Differential physico-chemical tolerances of amphipod species revealed by field transplantations. Oecologia, 124, 1-7.

MacNeil, C., Elwood, R.W. \& Dick, J. T. A. (2000). Factors influencing the importance of Gammarus spp. (Crustacea : Amphipoda) in riverine salmonid diets. Archive für Hydrobiologie, 149, $87-107$

MacNeil C., Dick J. T. A., Elwood R. W. \& Montgomery W. I. (2001) Coexistence among native and introduced freshwater amphipods (Crustacea); habitat utilisation patterns in littoral habitats. Archive für Hydrobiologie, 151, 591 - 607.

MacNeil C., Dick J. T. A., Hatcher M. J. \& Dunn, A. M. (2003) Differential drift and parasitism in invading and native Gammarus spp. Ecography, 26, 467-473.

MacNeil C., Prenter J., Briffa M., Fielding N.J., Dick J.T.A., Riddell G.E., Hatcher M.J. \& Dunn A.M. (2004) The replacement of a native freshwater amphipod by an invader: roles for environmental degradation and intraguild predation. Canadian Journal of Fisheries and Aquatic Sciences, 61, 1627-1635.

MacNeil C. (2006) River Quality 2005. Government Laboratory, Department Environment, Food and Agriculture. Isle of Man Government. Available at http://www.gov.im/daff/enviro/govlabs/riverwater.xml 
MacNeil C., Dick J.T.A., Gell F.R., Selman R., Lenartowicz P. \& Hynes, H.B.N. (2009) A longterm study (1949-2005) of experimental introductions to an Island; freshwater amphipods

(Crustacea) in the Isle of Man (British Isles). Diversity and Distributions, 15, 232-241.

MacNeil, C. and Dick, J. T. A.(2011) Parasite-mediated intraguild predation as one of the drivers of co-existence and exclusion among invasive and native amphipods (Crustacea). Hydrobiologia, 665, $247-256$.

MacNeil C., Boets P., Lock K. \& Goethals P.L.M. (2013) Potential effects of the invasive 'killer shrimp' (Dikerogammarus villosus) on macroinvertebrate assemblages and biomonitoring indices. Freshwater Biology, 58, 171-182.

MacNeil, C., Dick, J.T.A., Alexander, M.E., Dodd, J.A. \& Ricciardi, A. (in press). Predators vs. Alien: differential biotic resistance to an invasive species by two resident predators. Neobiota.

Maynard B., Wellnitz J.T.A., Zanini N., Wright W.G. \& Dezfuli B.S. (1998) Parasite-altered behaviour in a crustacean intermediate host: field and laboratory studies. Journal of Parasitology, 84, 1102-1106.

Newman R.M. \& Waters T.F. (1984) Size-selective predation on Gammarus pseudolimnaeus by trout and sculpins. Ecology, 65, 1535-1545.231. 
Petren K. \& Case T.J. (1996) An experimental demonstration of exploitation competition in an ongoing invasion. Ecology, 77, 118-132.

Pinkster S., Scheepmaker M., Platvoet D. \& Broodbakker N. (1992) Drastic changes in the amphipod fauna (Crustacea) of Dutch inland waters during the last 25 years. Bijdragen tot de Dierkunde, 61, 193-204.

Polis G.A., Myers C.A. \& Holt R.D. (1989) The ecology and evolution of intraguild predation: potential competitors that eat each other. Annual Review of Ecology and Systematics, 20, 297-330.

Rachalewski M., Banha F., Grabowski M. \& Anastacio P.M. (in press) Ectozoochory as a possible vector enhancing the spread of an alien amphipod Crangonyx pseudogracilis. Hydrobiologia.

Ryan F. (2001) River Corridor Survey 2000. Colby River. Manx Wildlife Trust, Tynwald Mills, St. John's, Isle of Man.

Sala O.E., Chapin F.S., Armesto J.J., Berlow E., Bloomfield J., Dirzo R. et al. (2000) Global biodiversity scenarios for the year 2100. Science, 287, 1770-1774.

Settle W.H. \& Wilson L.T. (1990) Invasion by the variegated leafhopper and biotic interactions: parasitism, competition, and apparent competition. Ecology, 71, 1461-1470.

Strayer D.L. (2009) Alien species in fresh waters: ecological effects, interactions with other stressors, and prospects for the future. Freshwater Biology, 55, (suppl. 1), 152-174. 
Strayer D.L. \& Dudgeon D. (2010) Freshwater biodiversity conservation: recent progress and future challenges. Journal of the North American Benthological Society, 29, 344-358

Sykes J.M., Lane A.M.J. \& George DG (1999) The United Kingdom environmental change network: protocols for standard measurements at freshwater sites. Centre for Ecology and Hydrology. Natural Environment Research Council. Huntingdon, Cambs.

Turnbull D.A. \& Bevan J.R. (1995) The impact of airport deicing on a river: the case of the Ouseburn, Newcastle Upon Tyne. Environmental Pollution, 88, 321-332.

Walley W.J. \& Hawkes H.A. (1996) A computer-based reappraisal of the biological monitoring working party scores using data from the 1990 river quality survey of England and Wales. Water Research, 9, 2086-2094.

Wright J.F, Moss D., Armitage P.D. \& Furse M.T. (1984) A preliminary classification of runningwater sites in Great Britain based on macro-invertebrate species and the prediction of community type using environmental data. Freshwater Biology, 14, 221-256. 
Table 1 Physicochemical characteristics of river $(\mathrm{R})$ and pond $(\mathrm{P})$ habitats in transplant experiments $($ mean $\pm \mathrm{SE})$

\begin{tabular}{ccccc}
\hline Site and habitat & $\begin{array}{c}\text { Oxygen } \\
\text { saturation } \\
(\%)\end{array}$ & $\begin{array}{c}\text { Biochemical } \\
\text { oxygen } \\
\text { demand } \\
\text { BOD }_{5} \\
\left(\mathrm{mg} \mathrm{L}^{-1}\right)\end{array}$ & $\begin{array}{c}\text { Conductivity } \\
\left(\mu \mathrm{S} \mathrm{cm}^{-1}\right)\end{array}$ & $\mathrm{pH}$ \\
\hline Rivers & & & \\
R1 & $96(2)$ & $<2$ & $183(12)$ & $7.2(0.2)$ \\
R2 & $102(4)$ & $<2$ & $200(22)$ & $6.9(0.01)$ \\
R3 & $98(2)$ & $<2$ & $157(6)$ & $7.9(0.01)$ \\
R4 & $92(2)$ & $<2$ & $182(6)$ & $7.6(0.2)$ \\
Ponds & & & & \\
P1 & $26(2)$ & $5(1)$ & $197(12)$ & $7.1(0.1)$ \\
P2 & $32(2)$ & $3(1)$ & $192(15)$ & $7.0(0.1)$ \\
P3 & $24(1)$ & $5(1)$ & $245(27)$ & $7.8(0.2)$ \\
P4 & $28(1)$ & $6(2)$ & $300(22)$ & $7.6(0.1)$ \\
\hline
\end{tabular}


Table 2 Mean values (and ranges) of environmental variables and loadings of the first three principal component $(\mathrm{PC})$ axes for the Colby and Grenaugh sites. Only highest loadings $(>0.06)$ are shown for clarity. (Transformations: $\mathrm{A}=\operatorname{arcsine}, \mathrm{L}=\log _{10}(\mathrm{x}+1)$ or $\log _{10}$ if $\mathrm{x}$ is never zero, $\mathrm{U}$ refers to untransformed data).

\begin{tabular}{|c|c|c|c|c|c|c|c|}
\hline \multirow[t]{2}{*}{ Variable } & \multicolumn{5}{|c|}{ Colby } & \multicolumn{2}{|c|}{ Grenaugh } \\
\hline & $\begin{array}{l}\text { Mean } \\
\text { values }\end{array}$ & PC1 & PC2 & PC3 & PC1 & $\mathrm{PC} 2$ & PC3 \\
\hline Depth $(\mathrm{cm}) \mathrm{L}$ & 21.9 & 0.62 & & & 0.69 & & \\
\hline Current velocity $\left(\mathrm{ms}^{-1}\right) \mathrm{U}$ & 0.4 & -0.85 & & & & -0.70 & \\
\hline Percentage of riffle A & 30 & -0.71 & & & -0.66 & & \\
\hline Substratum heterogeneity $U$ & 3.7 & & -0.81 & & & & \\
\hline Mean substratum particle size $\mathrm{U}$ & -1.2 & & & 0.71 & & & \\
\hline Minimum dominant particle size $U$ & $\mathrm{U} \quad 3.8$ & & & & & & \\
\hline Maximum dominant particle size $U$ & $U-7.0$ & & & 0.63 & & & \\
\hline Modal dominant particle size $U$ & -0.3 & & & & & & 0.63 \\
\hline Tree canopy cover $(\%)$ A & 5 & & & & & & \\
\hline Macrophyte cover (\%) A & 30 & 0.68 & & & 0.76 & 0.60 & \\
\hline Litter cover $(\%) \mathrm{A}$ & 5 & & & & & & 0.61 \\
\hline Eigenvalue & & 7.01 & 4.35 & 1.25 & 6.67 & 4.09 & 1.95 \\
\hline$\%$ variance explained & & 35.7 & 22.9 & 8.2 & 30.9 & 20.3 & 9.1 \\
\hline
\end{tabular}




\section{Figure Legends}

Fig. 1 Distribution of amphipods on the Isle of Man in 2009. R1-R4 and P1-P4 indicate river sections and ponds respectively, used for transplant experiments. Locations of the Colby and Grenaugh River sampling sites, used for microdistribution/drift studies are also indicated. Blank circle indicates no amphipods detected in pond/reservoir.

Fig. 2 Mean ( \pm SE) survivorship of (a) G. d. celticus in ponds (P1-4) and adjacent river sections (R1-R4) and (b) C. pseudogracilis and G. d. celticus in ponds (P1-4), over a two week period.

Fig. 3 Mean $( \pm \mathrm{SE})$ survivorship of C. pseudogracilis and G. d. celticus in single species and mixed species bioassay tubes in (a) the Colby River and (b) the Grenaugh River.

Fig. 4 Relationship between percentage relative abundance of C. pseudogracilis in patches of riverbed with respect to principal component PC1 'flow regime/macrophyte cover' in respect of (a) the Colby River and (b) the Grenaugh River.

Commented [J R7]: What are the lines on the figures? You Commented [o $\mathbf{R 7 ] : ~ W h a t ~ a r e ~ t h e ~ l i n e s ~ o n ~ t h e ~ f i g u r e s ? ~ Y o u ~}$
need to explain what they represent. If they are regression lines you should include the regression statistics. 
Fig. 5 Mean ( \pm SE) survivorship of (a) all three amphipod species by themselves and (b) C. pseudogracilis by itself or in the presence of either G. d. celtcius or G. pulex after $24 \mathrm{~h}$ in water of $20 \%, 30 \%$ and $40 \%$ saturation

Fig. 6 Relative abundance of (a) C. pseudogracilis and G. d. celticus in benthic and drift samples in the Colby River and (b) C. pseudogracilis and G. pulex in benthic and drift samples in the Grenaugh River

Fig. 7 Mean $( \pm$ SE) (a) \% of amphipods in light and (b) activity level of amphipods (light/dark results combined for clarity). 